\title{
Study on the Interaction Development Strategy Between Logistics Enterprises and Manufacturing Enterprises
}

\author{
Shijun Yuan \\ Hunan Vocational College of Modern Logistics \\ Changsha, China 410131
}

\author{
Jianhua Chen* \\ Hunan Vocational College of Modern Logistics \\ Changsha, China 410131 \\ *Corresponding Author
}

\begin{abstract}
A logistics company is a third party logistics enterprise reorganized from manufacturing enterprises through restructuring, in order to fully meet the development needs of manufacturing enterprises, which constantly explores the logistics strategy of its logistics information development. And through the comprehensive integration of logistics resources, achieve the development of linkage with manufacturing enterprises.
\end{abstract}

Keywords-logistics enterprise; interactive development; informatization; strategy

\section{INTRODUCTION}

A logistics enterprise, as a third party logistics enterprise which is separated from manufacturing enterprise, is greatly influenced by the traditional logistics operation mode. In the rapid development environment of social logistics enterprises, it is urgent to integrate resources, logistics informatization development field carries on the innovation development to enhance the enterprise's core competitiveness.

\section{ANALYSIS OF A LOGISTICS ENTERPRISE'S OPERATION STATUS}

\section{A. Long Time in Stock and Serious Storage of Goods}

A logistics enterprise lacks the information idea and technical support at present, and is used to regard the warehouse as the warehouse where goods are stacked. According to statistics, the average inventory time of this enterprise is 35 days, while the average inventory time of international advanced enterprises is 5-7 days. The long period of storage pressure means the decline of capital efficiency and turnover speed of enterprises, the inefficient investment of liquidity and the huge hidden economic loss.

\section{B. The Problem of Enterprise Informatization Is That It Pays More Attention to Investment, Less Use, More \\ Internalization and Less Socialization}

The information level of A logistics enterprise is relatively high in the whole province and all over the country, but it is still not many that actively use information means to shorten the inventory time, improve the warehouse turnover rate and reach the international advanced level. Many enterprises focus on the management of enterprise assets, human resources and trade secrets, and pay less attention to the sharing of information resources and unblocked channels of upstream and downstream industries and related enterprises. The isolated enterprise informatization means the rise of individual enterprise informatization cost and the decrease of logistics industry informatization benefit, which means huge fixed assets precipitation and loss.

\section{A LOGISTICS INFORMATIZATION DEVELOPMENT STRATEGY}

The leaders of A logistics company put forward the establishment of an information system for the manufacturing customers' demand for logistics informatization: a basic system (road transportation management integrated service system) and two application platforms (logistics E-connected mobile phone network control platform, logistics platform).

\section{A. The Construction of Logistics Management Information System}

In order to build a complete information system, the company attaches great importance to the overall planning, and configuring the storage management system, transportation management system, remote video monitoring system, logistics management information system, ,decision management system of purchasing and marketing management and so on, which provides a technical platform for manufacturing enterprise logistics to realize operation process, management standardization and decision-making science.

Logistics management information system is a set of application software system to provide logistics management. The system can exchange data from cement (or other manufacturing products) sales systems, warehousing systems, transportation management systems, and remote video systems At the same time, the system also includes logistics cost accounting, logistics cost comparison, logistics cost analysis and other management modules. Through the logistics management information system, the enterprise management can analyze all the operation data and management data of the distribution center of each branch factory, and provide decision 
support for the logistics management, while reducing the cost of human resources, the timely rate of decision-making has been increased by $90 \%$, and the accuracy rate has been raised to $99.999 \%$.

\section{B. Using Logistics Information Management System to Optimize Supply Chain Management Process}

The third party logistics information integration platform of A logistics takes the logistics related links (order management, transportation, warehousing, finance, and basic data) as a whole to carry on the process reengineering optimization: take the customer as the center, take the order as the main line, Sort out the business process.

Through the construction of the third party logistics information integration platform, the core competitiveness of logistics service is further enhanced, make A logistics enterprises form closer strategic alliance with customers and suppliers, to achieve a wider range of information sharing, cost savings, create A logistics companies and customers, suppliers in the logistics supply chain a three win situation.

Logistics A is mainly engaged in the distribution and third party logistics in the supply chain management. With the help of the information link, it has initially realized the integrated management of the supply chain among manufacturing enterprises and distributors, retailers and even end users. It brings many benefits to customers, such as lower cost, shorter order completion cycle, higher delivery rate on time, better response ability of enterprises and so on.

\section{Construction of Logistics Network System Based on Supply Chain Management and Value Chain Coordination}

A logistics has constructed a logistics network system based on supply chain management and value chain coordination with manufacturing industry linkage development. The essence of supply chain management is to make use of the external resources of enterprises to respond to the market demand quickly. Enterprises only need to grasp the core competitiveness and the market two parts, then they can make use of the resources of other enterprises to make their products low cost and high quality. Update timely and other aspects to occupy a competitive advantage. Value chain coordination shows that enterprises must adhere to the concept of cooperation and win-win development to participate in market competition, actively coordinate the interests of upstream and downstream enterprises and related enterprises, and share their share in the process of making bigger "cake" and "cake" quickly. Therefore, according to the requirements of modern logistics, logistics guides enterprises to reshape their business processes, change the traditional management mode of "single fight" and "winner-take-all", and take the management thinking of systematization and partnership, in order to form a destiny community with the manufacturing industry and develop together.

\section{Constructing Virtual Logistics System Based on Fourth Party Logistics}

Fourth Party Logistics (4PL) is actually a virtual logistics that relies on the best third-party logistics providers, technology providers, management consultants and other value-added service providers, plus the capabilities of customers. Effectively adapt to diverse and complex needs, provide unique and extensive solutions for manufacturing customers, and bring benefits to customers in the entire supply chain.

\section{E. Construction of Logistics Information Platform}

A logistics company cooperated with enterprises, established Hunan logistics information platform center, provided guarantee for the integration of logistics social resources. A logistics company cooperated with colleges and universities to set up a unified logistics information management platform in the whole province. It realizes the interconnection of logistics information and the sharing of data, which combines business flow, logistics flow, information flow and capital flow organically. Informationization has become an important driving force for A logistics company to carry out modern logistics construction in Xiangxi and even Hunan.

\section{COMPREHENSIVE RESOURCE INTEGRATION STRATEGY - IMPLEMENTATION OF LINKED DEVELOPMENT WITH MANUFACTURING INDUSTRY}

\section{A. Build An Independent Logistics Company to Design the Process}

In order to avoid repeated construction and waste of logistics resources due to the division of logistics activities, manufacturing enterprises must realize standardization, specialization and information. However, the realization of standardization must unify transportation management standard, warehouse management standard, storage network design standard, inventory management standard and service supplier selection standard. The realization of specialization must realize the knowledge specialization of logistics staff. The realization of informatization must establish logistics information system, and the final realization of these three (Standardization, specialization and informatization) needs strong executive organization, and the establishment of independent A logistics company can be well controlled and managed, A logistics company as the main body can also be well linked with the development of the manufacturing industry as the goal of the integration of resources. In order to realize the linkage development with the manufacturing industry and meet the logistics service demand of the manufacturing industry, there must be a standardized operation process, so the logistics company has carried out the process design from the inside and outside of the enterprise.

\section{B. Integration of Road Transportation Resources}

1) Use of capacity integrated management system: The location information of the vehicle is the basic information that any logistics management system must rely on. Without knowing the location information system of the vehicle, the location information system of the vehicle will not be able to play its role. A logistics company currently applies logistics E mobile location technology to achieve vehicle location 
information collection and processing. A logistics company, whether it is its own driver or the individual driver of the consortia, has a mobile phone, and in most cases the driver is with the vehicle, therefore, the location of the vehicle or cargo can be obtained by mobile phone location.

2) Building up virtual fleet to accumulate cooperative transport capacity for enterprises: A Logistics Company requires each individual first-time partner to register in a virtual fleet of its own integrated capacity management system (Registration requires only a short message from the driver without any other cost.) and record the vehicle information of the driver's car, the box type, the usual direction and so on, and the driver's identity card, driver's license, driving certificate information (the system is connected with the public security department's citizenship certificate inquiry and verification center, and can verify the real and false identity card in real time). In this way, A logistics can accumulate all the cooperating vehicles in the system, and can understand the location distribution of all the vehicles at any time through the positioning function of the system, so as to cooperate with them again and make these vehicles become the effective resources for the development of A logistics.

3) Fast scheduling and efficiency improvement: As long as the enterprise dispatcher enters a query condition in his virtual motorcade or in the online garage of the integrated capacity management system, he can immediately retrieve the current position, type of vehicle, and the usual flow to the vehicle that meets the requirements of the mission, and can immediately send the task content directly to the driver's mobile phone. Generally, as long as the price is appropriate, there will always be a driver to accept the task.

4) Job tracking, strengthening management: After the new waybill is entered in the transportation bill management of the integrated capacity management system, the dispatcher can associate the carrier vehicle with the waybill through the dispatching operation. In this way, for all the waybills, we can clearly understand the contents of the waybills, and the information of the carrying vehicles. You can easily click the mouse to get the latest location of any waybills, and drivers can report their work status directly through simple SMS instructions or built-in menus on their phones (for example, malfunctions, arrival, etc.) These states are immediately displayed in the waybill status of the capacity Integration Management system. This kind of function can make the management level of the enterprise raise a level without doubt.

5) Integration of storage resources: A logistics company is more inclined to own storage resources than transportation resources. Because the cost of storage resources is relatively low, and the investment of storage resources will bring land value-added and other additional benefits. However, with the acceleration of urbanization, some warehouses located in the suburbs have been requisitioned for commercial or residential land, which makes the city warehouse resources become more and more tense. A logistics company integrates storage resources and improves warehouse utilization by establishing storage resource database, constantly developing storage resources, paying attention to the dynamic function of warehouse and taking over the warehouse of the already cooperative manufacturing enterprise.

6) Integration of customer resources: After a logistics company officially operated, it changed its concept and strengthened the integration of customer resources. On the one hand, it strengthened the further deep cooperation with Huazhong cement; on the other hand, it actively expanded the market.

The integration of customer resources of A logistics company is two things at the operational level: one is to retain old customers, the other is to develop new customers. Since the cost of developing new customers is often five times that of retaining old customers, the focus of customer resource integration should be on old customers. And the demonstration effect of the old customer has the promotion function to the development of the new customer. At present, A Logistics's annual customer turnover rate is less than $2 \%$, while the number of customers in the manufacturing industry is growing at an average annual rate of $30 \%$.

\section{PERFORMANCE APPRAISAL OF SUPPly CHAIN: THE GUARANTEE OF THE SUCCESS OF LINKED DEVELOPMENT}

Logistics performance evaluation is based on modern information technology, information transmission and feedback timely, accurate performance evaluation is a dynamic process of constantly controlling and correcting work. The main functions of the performance evaluation of logistics service in the linkage development of A logistics and manufacturing industry are as follows:

- Supervision. It mainly evaluates the logistics work that has happened and reports the results to managers and manufacturing customers. The typical supervision index is composed of service level index and logistics cost index.

- Control. It is carried out mainly in the activities of the evaluation and control. Under the control of the activities, the managers of the A logistics can correct the mistakes before the major losses, improve the logistics procedures, and bring them into the normal state when it deviates from the right track. The most common control method is direct observation. At present, A logistics managers use computer system to evaluate the operation of employees and correct the problems immediately.

- Motivating employees. At present, the A logistics mainly pay the remuneration according to performance, and in this way, warehouse workers and transport personnel, etc. can be encouraged to achieve higher productivity.

\section{CONCLUSION}

A logistics company in the development process of the linkage with the manufacturing industry, constantly bold to 
innovate, seek a breakthrough, the comprehensive implementation of information technology transformation to make their own with the manufacturing industry linkage development of the basic conditions; Under the premise of continuously improving its service ability and service level, comprehensive resource integration, linkage and development with manufacturing industry. The logistics performance evaluation system based on supply chain is established to ensure the sustainability of the development of linkage with manufacturing industry.

\section{REFERENCES}

[1] Huang Fuhua, Gu Hanwen. Discussion on coordinated Development of Modern Manufacturing Industry and Logistics Industry in China [J]. Chinese circulation economy. 2009(08) .

[2] Wang Maolin, , Liu Binglian. Problems and Trends in the Linkage Development of Manufacturing Industry and Logistics Industry [J]. modern management science. 2009(03) .

[3] Qi Wenchang. Study on the Mechanism and Mode of the Linkage Development of Manufacturing Industry and Logistics Industry [J]. Science and Technology Innovation and Application. 2015(14). 